\title{
Soil Application Effects of Metarhizium anisopliae on Japanese Beetle (Coleoptera: Scarabaeidae) Behavior and Survival in Turfgrass Microcosms
}

\author{
MICHAEL G. VILLANI, STEPHEN R. KRUEGER,1 PETER C. SCHROEDER, \\ FRANK CONSOLIE, NANCY H. CONSOLIE, LUANN M. PRESTON-WILSEY, \\ AND DONALD W. ROBERTS ${ }^{1}$
}

Department of Entomology, New York State Agricultural Experiment Station, Cornel] University, Geneva, NY 14456

\begin{abstract}
Environ. Entamol. 23(2): 502-513 (1994)
ABSTRACT The effect of mycelial and conidial formulations of the insect pathogenic fungi, $M$. anisopliae, on the survival and behavior Japanese beetle, Popillia japonica Newman, larvae and ovipositing adults in turfgrass-soil microcosms was explored. Changes in Japanese beetle grub feeding site selection on sod roots, movement patterns, and survival in Metarhizium anisopliae inoculated soil were examined in greenhouse studies and through the use of radiographic analysis in the laboratory. Our studies indicate that the application of mycelial particles in soil affected the behavior of both larval and adult Japanese beetles. Japanese beetle grubs avoided soil that contained high concentrations of pathogen for up to $20 \mathrm{~d}$ after application. Conversely, the incorporation of mycelial particles increased oviposition in both choice and no choice studies. Our findings on scarab response to inundative applications of $M$. anisopliae mycelium may help explain some of the inconsistency in results that often occur when fungal pathogens are used to control insects in the field.
\end{abstract}

KEY WORDS Popillia japonica, Metarhizium anisopliae, soil insect behavior

ENTOMOPATHOGENIC FUNGI, INCLUDING the muscardine fungus Metarhizium anisopliae, are generating considerable interest from researchers and growers as biological control agents for scarab grubs in agricultural and horticultural crops (Samuels et al. 1990, Reid \& Cherry 1992, Zimmerman 1992, Milner 1992, Rath 1992). Although these fungi have caused high levels of insect mortality in the laboratory (Krueger et al. 1992, Krueger et al. 1991), population control from field releases are often less effective. Inconsistent control in the field results in part from our lack of basic understanding of the interactions between the fungus, the insect population and the soil environment (Villani et al 1992).

The importance of specific elements of the soil environment (water potential, temperature, relative humidity, clay content, biotic community, etc.) on fungus persistence have been independently studied (Hywel-Jones \& Gillespie 1990, Fargues 1976, Fargues 1983, Studdert et al. 1990, Walstad et al, Lingg \& Donaldson, 1981). Studies have also explored the impact of soil physical properties such as soil moisture and soil temperature on scarab/fungus interactions (Ferron 1967, Krueger et al. 1991, Reid \& Cherry 1992). To

\footnotetext{
' Boyce Thompson Institute, Cornell University, Ithaca, NY.
}

date, the direct impact of the inundative release of Metarhizium anisopliae on the behavior of the target insect population has not been studied.

In previous laboratory studies investigating the effects of $M$. anisopliae on Japanese beetle grubs (Krueger et al. 1991, Krueger et al. 1992), uniform incorporation of mycelial particles into small soil microcosms ( $30 \mathrm{~g}$ soil capacity) prohibited any measure of the behavioral response of the grubs to the fungus. Accordingly, the objectives of this research were to investigate the effects of $M$. anisopliae on the behavior and mortality of Japanese beetle larvae and adults in complex microcosms. Effects of $M$. anisopliae life stage, placement, and application rate on grub mortality and behavior over time were explored in greenhouse studies and through the use of radiographic analysis in the laboratory (Villani \& Wright 1988, Villani \& Nyrop 1991).

Chemical attractants, both specific and general, can serve as attractants to ovipositing females and larval stages of soil insects (Villani \& Wright 1990). The influence of natural products, emanating from host plants or from the soil, on Japanese beetle oviposition has not reported. However, previous studies have documented that Japanese beetle females will discriminate among oviposition sites differing in soil texture, 
soil moisture, and percent organic matter (Allsopp et al. 1992). M. anisopliae mycelia growing in the soil produce specific (Charnley \& St. Leger 1991, St. Leger et al. 1993, Roberts 1981) and nonspecific metabolites (i.e. $\mathrm{CO}_{2}$ ). For this reason, the effect of $M$. anisopliae mycelial particles on Japanese beetle oviposition was also studied in the laboratory.

\section{Materials and Methods}

Source of Insects, Soil and Fungus. Third instar Japanese beetle grubs collected from Syracuse, N.Y. during October 1991 were used in all soil studies. Grubs were placed in moist soil, covered with sod, and held for up to two months at $10^{\circ} \mathrm{C}$. Grubs were transferred to $23^{\circ} \mathrm{C}$ for $24 \mathrm{~h}$ before use in experiments. Adult Japanese beetles were collected twice daily from Japanese beetle traps baited with floral/sex lure. Beetles were placed into containers without soil for three days to feed on grape leaves and mate.

An unsterilized sandy loam with particle size distribution of $46.2 \%$ sand, $39.0 \%$ silt, and $14.8 \%$ clay was used in all bioassays. The organic matter content was $1.60 \%$; loose bulk density was $1.19 \mathrm{~g} / \mathrm{cm}^{3}$ and $\mathrm{pH}$ was 6.96 . Soil was sieved through window screening $(0.5 \times 0.5 \mathrm{~cm}$ mesh) for use in oviposition and radiographic studies. Unsieved field soil with larger rocks removed was used for the greenhouse study.

M. anisopliae (ARSEF 2547 Entomopathogenic Fungus Culture Collection, USDA-ARS Plant Protection Unit, Cornell University, Ithaca, NY 14853) was originally isolated from a diseased European chafer grub near Syracuse NY. Formulated mycelial granules $(250-500 \mu \mathrm{m}$ particle size) and unformulated conidia were prepared and stored as described by Krueger et al. 1992.

Greenhouse Study. One hundred and fifty-six painted wooden boxes, inside dimensions $26 \times$ $26 \times 9 \mathrm{~cm}$, were filled with $4.5 \mathrm{~kg}$ of moist soil $(20.7 \%(w / w))$. After filling each box, the soil was lightly tamped and $3 \mathrm{~g}$ of grass seed were evenly sprinkled on the soil surface. Twenty, thirdinstar Japanese beetle grubs were evenly distributed on the soil surface. Sod (consisting of $25 \%$ each of the 'Touchdown', 'Glade', 'Adelphi' and 'Gnome' Kentucky Bluegrass grass varieties) was cut to the inside dimensions of each box and placed on top of the soil. Microcosms were irrigated with 100-150 ml distilled water. To standardize the orientation of each box, one side of each box was arbitrarily assigned as 'front'. Microcosm orientation allowed us to randomly position the boxes in the greenhouse after the introduction of fungus and still determine grub location in relation to application pattern of fungal inoculum.

Six days after grub introduction, each box was assigned to one of three treatments: 1) broadcast
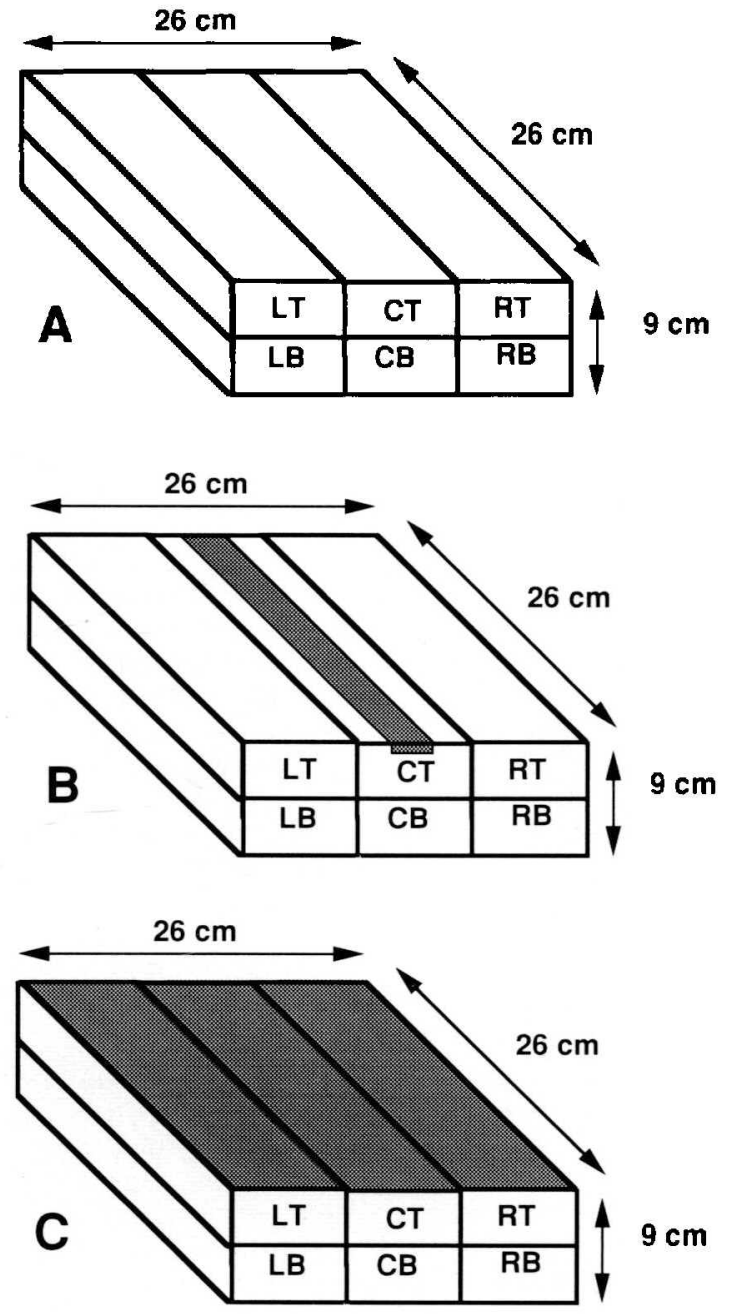

Fig. 1. Greenhouse microcosms. Microcosms were divided into six sections [top left (TL), top middle (TM), top right TR), bottom left (BL), bottom middle (BM) and bottom right (BR)] of equal soil volume. Mycelial particles were placed in a subsurface furrow (B), broadcasted at the soil-root interface (C), or were not applied (A).

$8.0 \mathrm{~g} \mathrm{M}$. anisopliae mycelial particles; 2) furrow $8.0 \mathrm{~g} M$. anisopliae mycelial particles; 3) check $0.0 \mathrm{~g} \mathrm{M}$. anisopliae mycelial particles. In boxes assigned a broadcast treatment, sod was temporarily removed and the fungus was sprinkled over the entire surface of soil (Fig. IC). In boxes assigned to a furrow treatment, sod was temporarily removed and the fungus was distributed in a $1.5 \mathrm{~cm}$ wide by $1.5 \mathrm{~cm}$ deep furrow, extending front to back (top-center) (Fig. 1B). The raised soil beside the furrow was pushed back to cover the fungus within the furrow before the sod was replaced. In the control treatment (checks), sod was temporarily removed but the soil was not inoculated with fungal particles (Figure 1A). 
Each box was irrigated with $200 \mathrm{ml}$ distilled water after inoculation and replacement of sod and were lightly watered (volume not recorded) twice before the first destructive sampling. Between the second and third destructive sampling, and after the third destructive sampling, the sod in each box was turned over and the bottom side of the sod was watered. Additional grass seed was added to the soil surface in each box and the sod was repositioned in its original orientation and the sod irrigated with an additional $200 \mathrm{ml}$ of water.

Grub condition (live or dead) and developmental stage (larvae, pre-pupae, pupae) were determined at 28 (Reading 1), 42 (Reading 2) and 49 (Reading 3) days after inoculation. At each reading, 39 boxes (13 per treatment) were destructively sampled by dividing the soil in each box into six equally wide $(8.7 \mathrm{~cm})$ sections relative to the 'front' of the microcosm: top right, top middle, top left, bottom right, bottom middle and bottom left. Bottom sections were designated as the bottom $4 \mathrm{~cm}$ of soil.

Thirty-nine boxes (13 per treatment) were left in the greenhouse and monitored for adult emergence. Microcosms were checked daily for emerged adults and living adults were removed and date noted. The microcosms were destructively sampled 106 days after inoculation as in readings 1-3.

Determination of Fungal Concentration. Samples were taken to determine fungal concentrations in the soil of six microcosms (two per treatment) at each reading. Soil in the boxes was divided into six sections (as described earlier) at each destructive sampling date. The soil in each sampled section was homogenized and one $25 \mathrm{~g}$ subsample was removed and air dried for 3 to 4 days. The dried soil from each cup was weighed, then blended with distilled water ( 1 part soil: 10 parts water) for $30 \mathrm{~s}$ in a commercial Waring blender. Immediately after the blender stopped, a $10 \mathrm{ml}$ sample was taken from the soil and water suspension. The sample was serially diluted with sterile distilled water plus $0.05 \%$ Tween 80 , and a $0.5 \mathrm{ml}$ aliquot of the dilution expected to yield $\approx 20-300$ pathogen colonies was spread on four replicate plates containing an oatmealiodine, selective growth medium (Chase et al. 1986). Appropriate dilutions for plating were determined from previous tests with fungusinoculated soil samples. Plates were incubated at $23^{\circ} \mathrm{C}$ for one week, and resulting fungal colonies were counted.

Statistical Analysis. Proportions of grubs (no. grubs recovered in section/no. grubs recovered in microcosm) and fungal concentrations were calculated for each soil section, and grouped for top and bottom sections, and left, middle, and right sections. Data were then transformed to square root of $Y+0.5$ (grub proportion) or $\log _{10}+1.0$ (colony forming unit [CFU] concen-

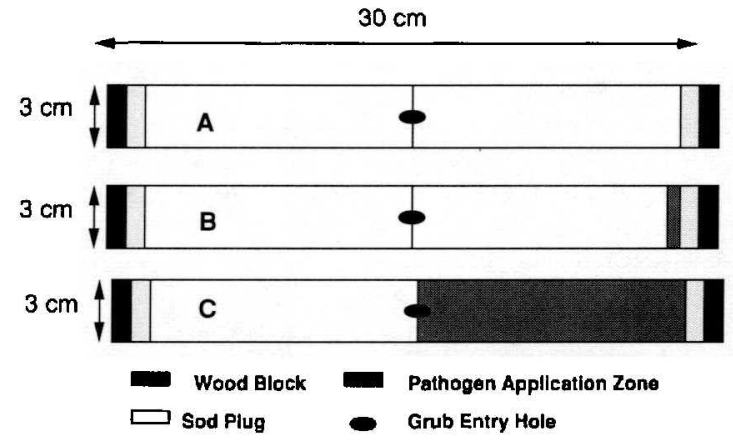

Fig. 2. Radiography microcosms. Paired soil microcosms were created in Plexiglas boxes with inside dimensions of $3 \times 3 \times 30 \mathrm{~cm}$. One side of each box was removable and contained a hole (approximately $\approx 1 \mathrm{~cm}$ in diameter) located in the center for the introduction of grubs. Duct tape covering the hole was removed to allow placement of grubs at the interface of the paired soil microcosms. Mycelial particles were placed broadcasted at the soil-root interface (B), incorporated into soil (C), or were not applied (A).

tration) and grub and CFU concentration 'profiles' were compared among different treatments and sample dates using a multivariate statistical analysis of variance (MANOVA) procedure (Johnson and Wichern 1982). Wilk's lambda and a $P<0.05$ was used in each MANOVA as the test criteria for differences between profiles. Differences in grub survival among microcosms receiving different fungal applications (broadcast vs. furrow) were tested using a two-tailed $t$-test for each sampling date.

The cumulative mean number of Japanese beetles emerged (not transformed) over six sample dates $(78,83,88,93,98 \& 103$ days) was analyzed using a MANOVA (one way fixed effects model) with the observations as multivariate responses over time (profile analysis). Fisher's protected LSD test was used to determine significant differences in cumulative emergence among treatments at 103 days (Johnson \& Wichern 1982.).

Radiography Studies. Each soil microcosm (Figure 2), regardless of treatment, contained $250 \mathrm{~g}$ of soil. Sod plugs were cut to the inside dimensions $(3 \mathrm{~cm}$ by $3 \mathrm{~cm}$ ) of each box, placed on both ends of soil with roots toward the center of the box, and held in place with a wooden block cut to the same dimensions as the sod. Because slight differences in soil compaction can affect grub movement patterns, the order that each box was filled with soil was alternated to reduce experimental bias. All boxes were filled $24 \mathrm{~h}$ before introduction of grubs into the microcosms. Grubs were introduced at the interface of the paired microcosm by placing an individual grub, head first into the center hole of each box. Each grub was observed for one minute after release and replaced with a different grub if it did not move 
into the soil. Boxes with paired microcosms were stored horizontally and at random compass directions, in complete darkness at $25^{\circ} \pm 2^{\circ} \mathrm{C}$ during each experiment. Radiographic techniques and equipment used in this study were identical to those described by Villani and Nyrop (1991). Radiographs were taken of all boxes in sets of eight at regular, predetermined time intervals. The location of each grub within the microcosms was marked on the radiograph and recorded as distance relative to the interface of the paired $\mathrm{mi}$ crocosms (to the nearest $\mathrm{cm}$ ).

Experiment 1. This experiment was conducted to determine the effect of placement of mycelial granules in microcosms on grub movement patterns (rate, direction and location) in the microcosms over time. Ninety-six microcosms were used in this experiment (4 treatments with 24 replicates per treatment). Treatments were: 1) the subsurface application of $2.0 \mathrm{~g}$ of $M$. anisopliae mycelial particles; 2) the corresponding subsurface check; 3 ) the incorporation of $2.0 \mathrm{~g}$ of $\mathrm{M}$. anisopliae mycelial particles into $125 \mathrm{~g}$ of soil and 4) the corresponding incorporation check.

For boxes receiving subsurface treatments, $250 \mathrm{~g}$ of soil was placed in each box and the soil was compressed to $21 \mathrm{~cm}(5 \mathrm{~cm}$ from each end) within the entire length of the box. After soil compression, in those subsurface boxes receiving fungus, $2.0 \mathrm{~g}$ of $M$. anisopliae mycelial particles were applied to one end, directly onto the soil surface. Sod and then wooden plugs were placed at both ends of the boxes in both the fungus treated and check boxes.

Boxes receiving the incorporated fungus treatments were filled in two stages. In one half of the fungus treated boxes, $125 \mathrm{~g}$ of untreated soil were placed into each box and compressed to $2.5 \mathrm{~cm}$ from one end of the box $(10.5 \mathrm{~cm} \times 3 \mathrm{~cm}$ $\times 3 \mathrm{~cm}$ soil block from the midline). Two grams of mycelial particles were then mixed uniformly into the remaining $125 \mathrm{~g}$ of soil which was then added to the opposite end of the box, on top of the existing soil and compressed as described above. In the second half of the fungus-treated incorporated boxes a similar protocol was followed except that the fungus-incorporated soil was added to each box first. Corresponding filling regimes were used for check boxes with the omission of mycelial particles from the soil. Microcosms were radiographed $2,6,26,98,266$, and $464 \mathrm{~h}$ after grub introduction and destructively sampled for grubs and mortality noted at $464 \mathrm{~h}$.

Experiment 2. This experiment was conducted to compare the effect of mycelial versus conidial preparations of $M$. anisopliae and the effect of mycelial application rate on differences in grub movement patterns (rate, direction and location). Sixty-four microcosms (4 treatments with 16 replicates per treatment)were prepared as described for incorporated treatments in Experiment 1.
Fungus applications (treatments) included $2.0 \mathrm{~g}$ $M$. anisopliae mycelial particles incorporated into $125 \mathrm{~g}$ soil (rate identical to Experiment 1), $0.2 \mathrm{~g} \mathrm{M}$. anisopliae mycelial particles incorporated into $125 \mathrm{~g}$ soil (log reduction), $1.85 \mathrm{mg}$ conidia incorporated into $125 \mathrm{~g}$ soil (rate determined by estimating conidia production of $2.0 \mathrm{~g}$ M. anisopliae mycelium) and an untreated (no fungus) check.

Microcosms were radiographed in sets of eight at $2,6,26,98$, and $266 \mathrm{~h}$, after insertion of a single grub through the hole at the midline. Grub position (location) relative to the midline of each microcosm was recorded. Microcosms were destructively sampled at $266 \mathrm{~h}$ and mortality of grubs noted.

Statistical Analysis. For both experiments the mean location relative to the release point (midline of microcosm) of grubs in the microcosms receiving fungus applications were compared with the mean location of grubs within microcosms receiving no fungus application. Although data were apparently non normal (apparent binomial), no standard transformations were available that broke the relationship between means and variances. A two-factor MANOVA (two way fixed effect model with interaction) with treatment (fungus application) and the order of filling boxes as main effects arranged in a factorial and the observations are multivariate responses over time. Analyses are equivalent to the profile analysis as described by Johnson \& Wichern (1982). Orthogonal comparisons were made for each time period of mean grub position within check (untreated) microcosms with mean grub position within fungus-treated microcosms and conidiatreated microcosms with mycelial particle treated microcosms.

Oviposition Study. The effect of incorporated mycelial particles on Japanese beetle oviposition was determined in a replicated choice and nochoice study. In each of three trials, twelve nochoice microcosm (six containing soil with incorporated mycelial particles [treated] and six containing only untreated soil [check]), and six choice microcosms (microcosms containing both treated and untreated soil) were used.

Microcosms consisted of a 'treatment' arena within a 'confinement' arena system. Arenas were made from rigid clear styrene plastic boxes. The inner or 'treatment' arena (12 $\times 8 \times 6 \mathrm{~cm})$ was divided in half with a vertical flat plastic insert to allow for two different soil treatments within the same 'treatment' arena. The upper edge of each insert was placed level with the soil surface so not to restrict surface movement of the adults between soil treatments. However, inserts prevented adults from traveling between differently treated soils below the surface.

The 'treatment' arena was placed into a larger 'confinement' arena $(18 \times 13 \times 10 \mathrm{~cm})$. Marble chips were used to fill the space between the two 
arenas. Water $(100 \mathrm{ml})$ was added to the marble chips to increase the humidity within the arenas. A Linden leaf was anchored onto the marble chips as a food source and replaced daily. Three female Japanese beetle adults were placed on the marble chips. A cover was added to the 'confinement' container.

Soil was prepared in $250 \mathrm{~g}$ batches, half of these batches received $2.0 \mathrm{~g} \mathrm{M}$. anisopliae mycelial particles mixed thoroughly into the soil (treated) and the remaining batches were left untreated (check). Each half of the 'treatment' arena received one $250 \mathrm{~g}$ batch of soil. "Treatment' arenas within the choice microcosms contained one batch of mycelial particle-treated and one batch of check (untreated) soil. 'Treatment' arenas within the no-choice microcosms contained two identical batches of mycelial particletreated or check (untreated) soil. To test if females preferred the left or right side of the microcosm, each choice and no-choice 'treatment' arena was oriented in a 'left' or 'right' position within the 'confinement' arena. Microcosms were than positioned randomly with regard to compass direction. Position effects were determined by comparing eggs in the 'left' vs. 'right' sides of each microcosm in no-choice microcosms.

All 'treatment' arenas were filled with soil $24 \mathrm{~h}$ before introduction of female adults. Microcosms were held at $25^{\circ} \mathrm{C}$ on a $12 / 12$ light/dark schedule. Seven days from inoculation, microcosms were destructively sampled and the number of eggs per treatment were counted.

A two-factor ANOVA was performed using test date (block) and choice (treatment) as main effects. Analysis tested for differences in total number and percentage of eggs between the two sides of the 'treatment' arena within the microcosm.

\section{Results}

Greenhouse Study. Effect of M. anisopliae Application. Significantly fewer grubs survived in broadcast treated microcosms compared with untreated microcosms on the second ( 42 days) and third (49 days) sampling dates (Table 1). Survival of grubs did not significantly differ between furrow and untreated microcosms on any destructive sampling dates. Emergence began 73 days after inoculation and concluded 103 days after inoculation. Emergence of adults was significantly different among treatments $(F=7.83 ; \mathrm{df}=$ $10,64 ; P=.0001)$. All grubs had pupated and emerged, or died in microcosms 106 days after inoculation.

Broadcast application of $M$. anisopliae to microcosms caused grub profiles to differ significantly between the vertically oriented (top and bottom) sections of the microcosms $(F=4.949$; $\mathrm{df}=1,72 ; P=0.0292)$ but not among the hori-
Table 1. Mean weighted grub counts from microcosms receiving no application (check), broadcast application, or furrow application of $\boldsymbol{M}$. anisopliae mycelial particles

\begin{tabular}{lcccc}
\hline \hline \multirow{2}{*}{ Treatment } & \multicolumn{4}{c}{ Sample date } \\
\cline { 2 - 5 } & 28 Days & 42 Days & 49 Days & 103 Days $^{a}$ \\
\hline Check & 17.1 & 16.0 & 16.4 & $12.3 \mathrm{~A}$ \\
Broadcast & 15.6 & $12.8^{*}$ & $11.0^{*}$ & $1.5 \mathrm{C}$ \\
Furrow & 16.4 & 15.9 & 15.6 & $8.8 \mathrm{~B}$ \\
\hline
\end{tabular}

* Significantly different from the check within the same sample date based on a two-tailed $t$-test $(P<0.05)$. Data were transformed to square root of $Y+0.5$ before analysis.

a Means followed by different letters are significantly different Fisher's protected least significant difference (critical difference $2.235 ; P>, 01$ ).

zontally oriented (left, middle, and right) sections of the microcosms $(F=0.701 ; \mathrm{df}=2,71$; $P=0.4995)$ (Figure 3). Vertical differences in grub profiles were significant on all sample dates (28 days: $F=6.058 ; \mathrm{df}=1,24 ; P=0.0214,42$ days: $F=14.222 ; \mathrm{df}=1,24 ; P=0.0009,49$ days: $F=12.690 ; \mathrm{df}=1,24 ; P=0.0016)$. In contrast, furrow application of $M$. anisopliae to microcosms caused grub profiles to differ significantly between the horizontally oriented sections of the microcosms $(F=10.214 ; \mathrm{df}=2,70 ; P=0.0001)$ but not the vertically oriented sections of the microcosms $(F=0.082 ; \mathrm{df}=1,71 ; P=0.7748)$. Horizontal differences in grub profiles were significant on the first two sample dates (Time 1 : $F=3.486 ; \mathrm{df}=2,22 ; P=0.0484$, Time $2: F=$ $5.217 ; \mathrm{df}=2,23 ; P=0.0135$ ) but only marginally significant on the third sample date $(F=3.018$; $\mathrm{df}=2,23 ; P=0.0686$ ).

Grub profiles across all sections significantly changed through time in both fungal treatments (Broadcast: $F=5.944 ; \mathrm{df}=10,134 ; P=0.0001$, Furrow: $F=4.819$; df $=10,136 ; P=0.0001$ ) (Figure 3). However, differences in grub profiles through time were only significant between the vertically oriented sections of the microcosms (Broadcast: $F=22.762 ; \mathrm{df}=2,72 ; P=0.0001$, Furrow: $F=29.814 ; \mathrm{df}=2,71 ; P=0.0001$ ) and not between the horizontally oriented sections of the microcosms (Broadcast: $F=1.090 ; \mathrm{df}=4$, 142; $P=0.3640$, Furrow: $F=1.466$; $\mathrm{df}=4,140$; $P=0.2158$ ).

Fungal Concentration Profiles. Profiles of mycelial particle concentrations in microcosms differed significantly among treatments $(F=$ 21.638; $\mathrm{df}=12,8 ; P=0.0001$ ) (Figure 3). Neither time $(F=0.579 ; \mathrm{df}=12,8 ; P=0.8102)$ nor the treatment by time interaction $(F=0.568$; $\mathrm{df}=12,8 ; P=0.8977$ ) affected fungal concentration. Profiles differed significantly between treatments both vertically (top vs. bottom) $(F=$ 9.506; $\mathrm{df}=4,16 ; P=0.0004$ ) and horizontally (left vs. middle vs. right) $(F=24.471 ; \mathrm{df}=6,14$; $P=0.0001)$. Fungal concentrations in microcosms that received a broadcast application (treatment) differed significantly from concentra- 

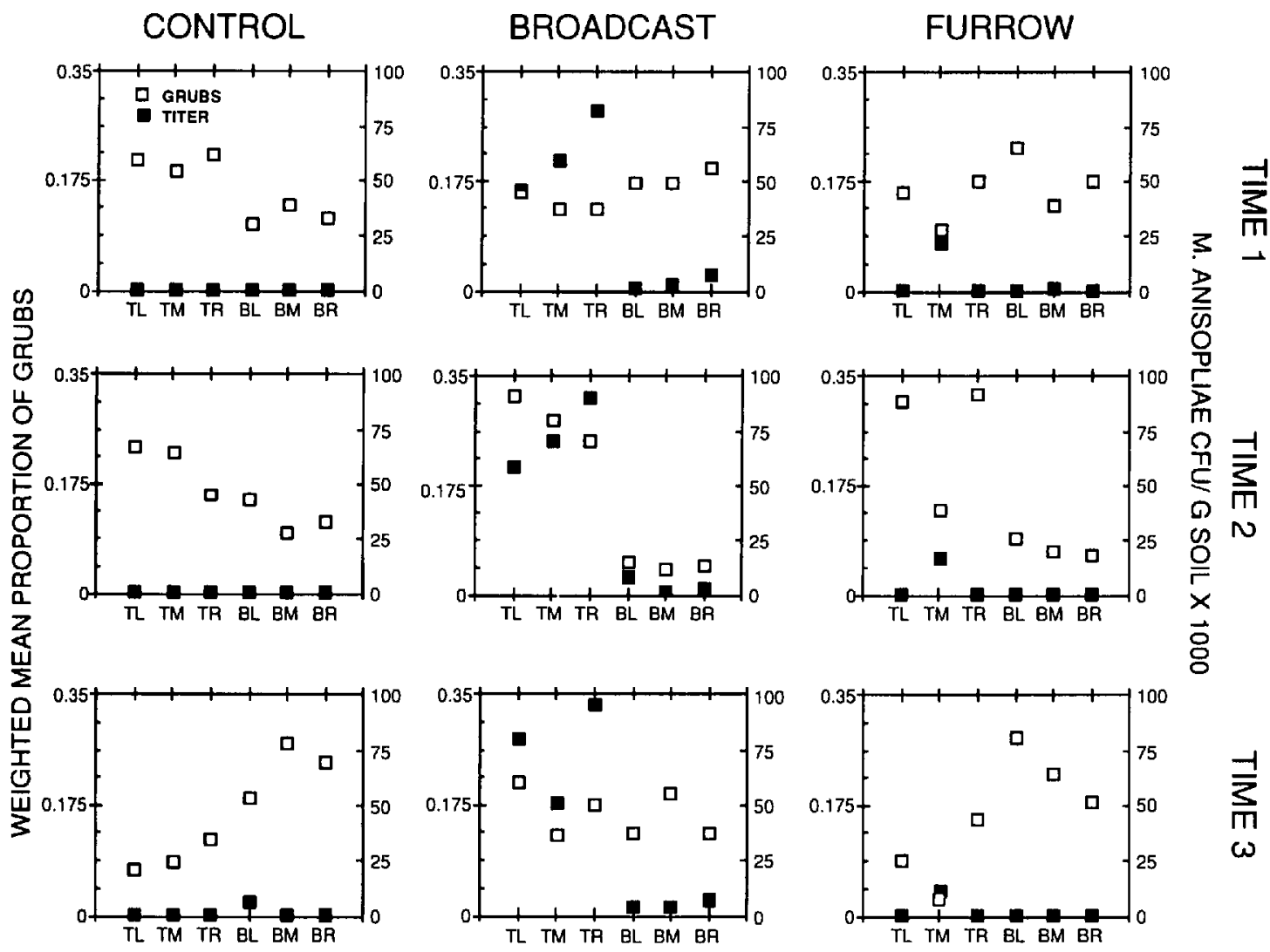

Fig. 3. Mean weighted proportion of grubs and absolute fungal titers for all time and treatment combinations in the various sections of destructively sampled greenhouse microcosms. Any grubs found in roots of sod were placed in the corresponding adjacent soil section.

tions in microcosms that received no fungal application (check). Differences were significant in all sections but were greatest in the top (site of application) ( $F=43.378$; $\mathrm{df}=1,6 ; P=0.0005$ ), the site of application, and the right section of the microcosms $(F=269.0 ; \mathrm{df}=1,6 ; P=$ 0.0001 ). The high fungal concentration in the right section of the arenas appears the result of a consistent, uneven pattern in the distribution of pathogen across the surface of the soil.

$M$. anisopliae concentration in microcosms that received a furrow application also differed significantly from the concentration in microcosms that received no application. The differences were significant between middle sections (site of application) only $(F=36.863 ; \mathrm{df}=1,6$; $P=0.0009$ ) and was greatest in the top sections (site of application) of the microcosms ( $F=$ 24.113; $\mathrm{df}=1,6 ; P=0.0027$ ).

Radiography. Experiment 1. Figures 4 and 5 show representative radiographs of microcosms that received the incorporated mycelium treatment and no treatment (check) respectively. Incorporation of mycelium caused significant changes in grub position over time $(F=2.537$, $\mathrm{df}=15,185 ; P=0.004)$, but no significant dif- ferences in grub position were caused by filling order, nor was there a significant treatment by filling interaction. Orthogonal comparisons between mean grub position within fungus treated microcosms and their corresponding check microcosms at each sample time $(2,6,26,98,266$, 464 hours after grub release) showed no significant differences in grub position at 2, 6, and 26 hours, although grubs crossed into soil containing mycelial particles only once during this period (Figure 6 (incorporated and check), Figure 7 (subsurface and check)). Significant differences between mean grub positions within mycelial particle-treated microcosms and their corresponding check microcosms were observed at $98 \mathrm{hrs}$ (incorporated vs. check: $F=11.227, P=0.0013$; subsurface Vs check: $F=8.357, P=0.0051$ ) and 266 hrs (incorporated Vs check: $F=10.914, P=$ 0.0015 ; subsurface Vs check: $F=5.983, P=$ $0.0169)$ after grub release. In microcosms containing $M$, anisopliae grubs moved consistently to the side of each microcosm containing no mycelial particles, but moved to either side of the check microcosms. At 464 hours after placement of grubs in soil, grubs had consumed all of the turf 


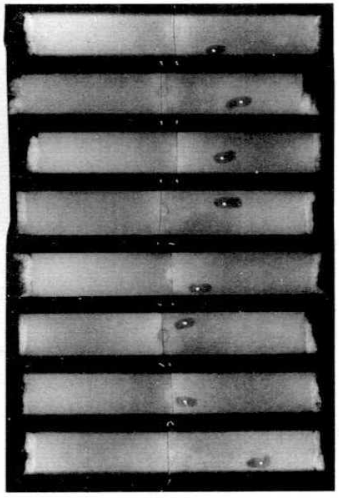

$6 \mathrm{Hr}$

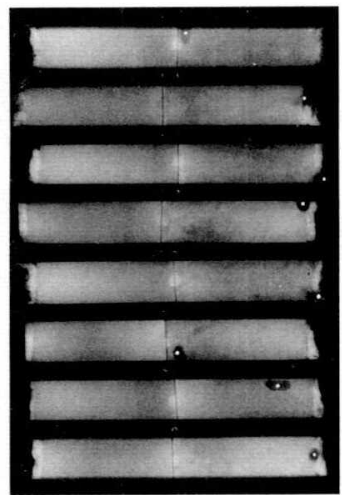

$98 \mathrm{Hr}$

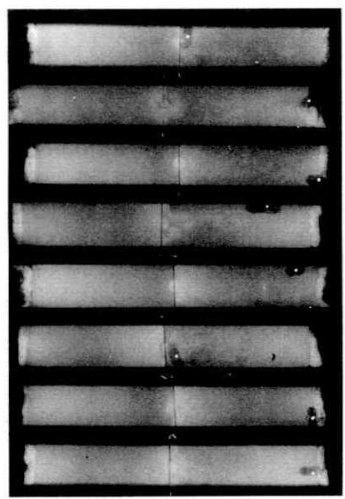

2547

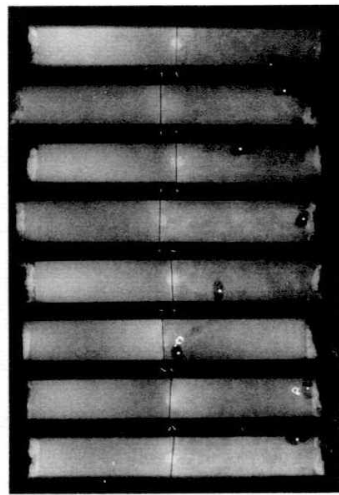

$464 \mathrm{Hr} \quad 2547$

Fig. 4. Radiograph of mycelium containing microcosms of incorporated experiment. Mycelium incorporated soil was placed on the right half of each microcosm. Time lapse radiographs of one block of microcosms in incorporated experiment. Six hours, twenty-six hours: grubs are moving from release point in microcosm center away from mycelium incorporated side of microcosm; ninety-eight hours: grubs are feeding in roots on untreated side of microcosms; four hundred sixty-four hours: grubs have destroyed roots on untreated end of microcosms and burrowing through soil in search of food but have not crossed into treated side of microcosms.

roots in the check microcosms and all of the roots on the non-fungus side of the treated microcosms. Although live roots were present in the side of the microcosms with the incorporated and subsurface fungus treatments, grubs were never observed feeding on roots. At 464 hours, grub position within microcosms containing incorporated applications of fungus were significantly different from the checks $(F=7.117, F=0.0095$ ), whereas grub positions within microcosms containing subsurface application of fungus were not significantly different from the checks $(F=$ $0.345, F=0.5588$ ).

Experiment 2. Application of fungus to microcosms caused significant differences in grub po-

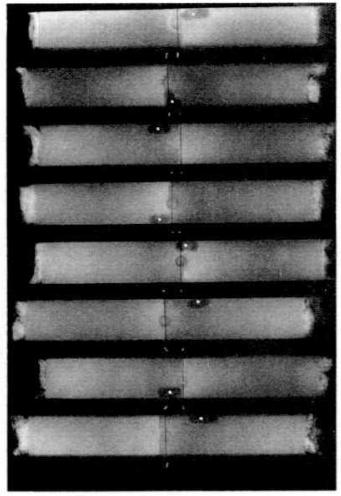

$6 \mathrm{Hr}$ Check

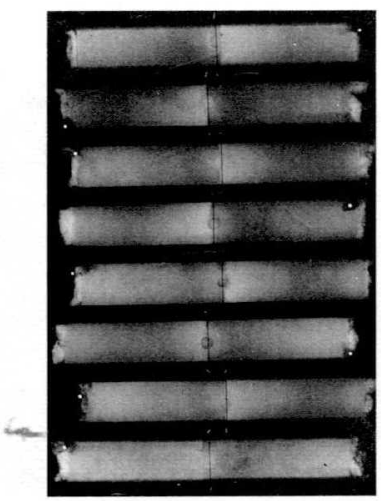

$98 \mathrm{Hr}$ Check

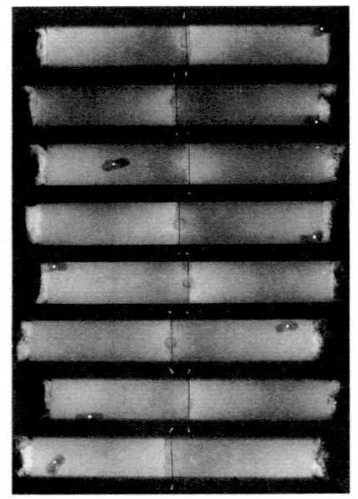

$26 \mathrm{Hr}$ Check

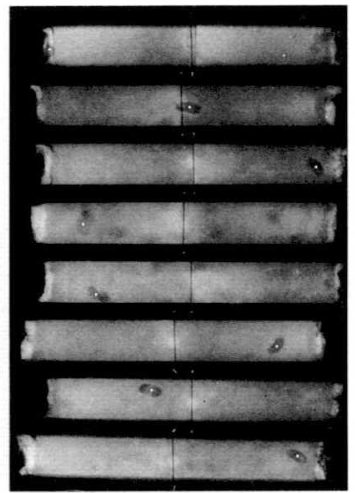

$464 \mathrm{Hr}$ Check
Fig. 5. Radiograph of check microcosms of incorporated experiment. Time lapse radiographs of one block of microcosms in incorporated experiment. Six hours: grubs are moving from release point in microcosm center; twenty-six hours: grubs can be seen moving in randomly to either end of the microcosms in search of roots; ninety-eight hours: grubs are feeding in roots on either side of microcosms; four hundred sixtyfour hours: grubs have destroyed roots on both ends of microcosms and burrowing through soil in search of food.

sition over time $(F=2.873, \mathrm{df}=12,185, F=$ $0.0016)$ when compared with untreated microcosms. No significant differences in grub position were caused by the order of microcosm filling or treatment by filling interaction. Orthogonal comparisons of mean grub position within untreated microcosms with mean grub position within treated microcosms showed significant differences at each time period ( 2 hrs: $F=$ 13.937, $F=0.0005 ; 6$ hrs: $F=19.658, F=$ $0.0031 ; 26$ hrs: $F=13.159, F=0.0007$; 98 hrs: $F=8.209, F=0.0061 ; 266$ hrs: $F=16.906, F=$ 0.0001 . Similar significant differences were observed between mycelium and conidial treatments ( 2 hrs: $F=11.175, F=0.0016$; 6 hrs: $F=$ $4.826, F=0.0327 ; 26$ hrs: $F=5.698, F=0.0208$; $98 \mathrm{hrs}: F=13.876, F=0.0005 ; 266 \mathrm{hrs}: F=$ $11.639, F=0.0013$ ) (Figure 8 ). 

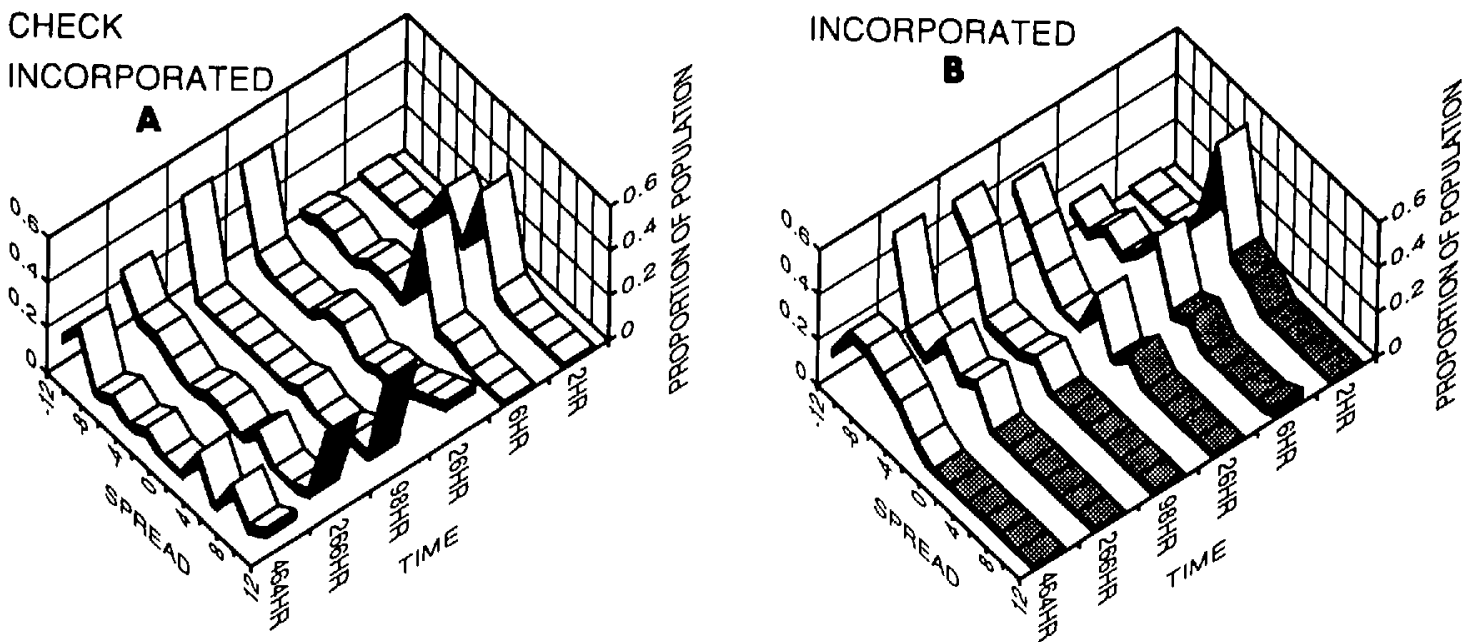

Fig. 6. Response of Japanese beetle grub population to the presence of incorporated mycelium. Graph indicates shifts in grub population ( $z$-axis) in radiographic microcosms ( $x$-axis) over time ( $y$-axis). Shaded area denotes presence of mycelial particles in chamber.

These results agree with the results in Experiment 1 and also indicate that the presence of conidia does not significantly affect observable grub movement patterns in soil when compared to conidia-free microcosms. Grub position in microcosms receiving the high concentration of mycelial particles was significantly different from their position in microcosms receiving the low rate treatments only in the radiographs taken at 2 hrs $(F=11.193, F=0.0016)$. Significant differences in grub position between the two mycelial rates were not detected at any other time period.

Oviposition. Significant differences in the mean number of eggs oviposited per microcosm differed among the three test dates (Time 1: $55.28 \pm 4.891$; Time 2: $47.67 \pm 3.909$; Time 3: $34.72 \pm 2.99 ; F=9.611 ; \mathrm{df}=2,45 ; F=0.0003)$, and among treatments (no-choice check: $36.28 \pm$ 3.953; no-choice mycelium: $59.78 \pm 3.953$ choice: $41.611 \pm 3.394 ; F=13.327 ; \mathrm{df}=2,45$; $F=0.0001)$; however, no test by treatment interactions were detected $(F=0.242 ; \mathrm{df}=4,45 ; F=$ 0.9131 ) indicating that while the total number of eggs oviposited changed over time, the impact of treatment was consistent. A comparison of the number of eggs laid between the two sides of the microcosms did not differ among tests $(F=3.178$, $\mathrm{df}=2,45 ; F=0.0512$ ), but did differ among treatments $(F=4.155 ; \mathrm{df}=2,45 ; F=0.0221)$. No test by treatment interaction was detected $(F=$ $0.834 ; \mathrm{df}=4,45 ; F=0.5110$ ).

Japanese beetle females oviposited a greater number of eggs on the mycelial particle-treated side of each microcosm $(28.44 \pm 3.16)$ than in the
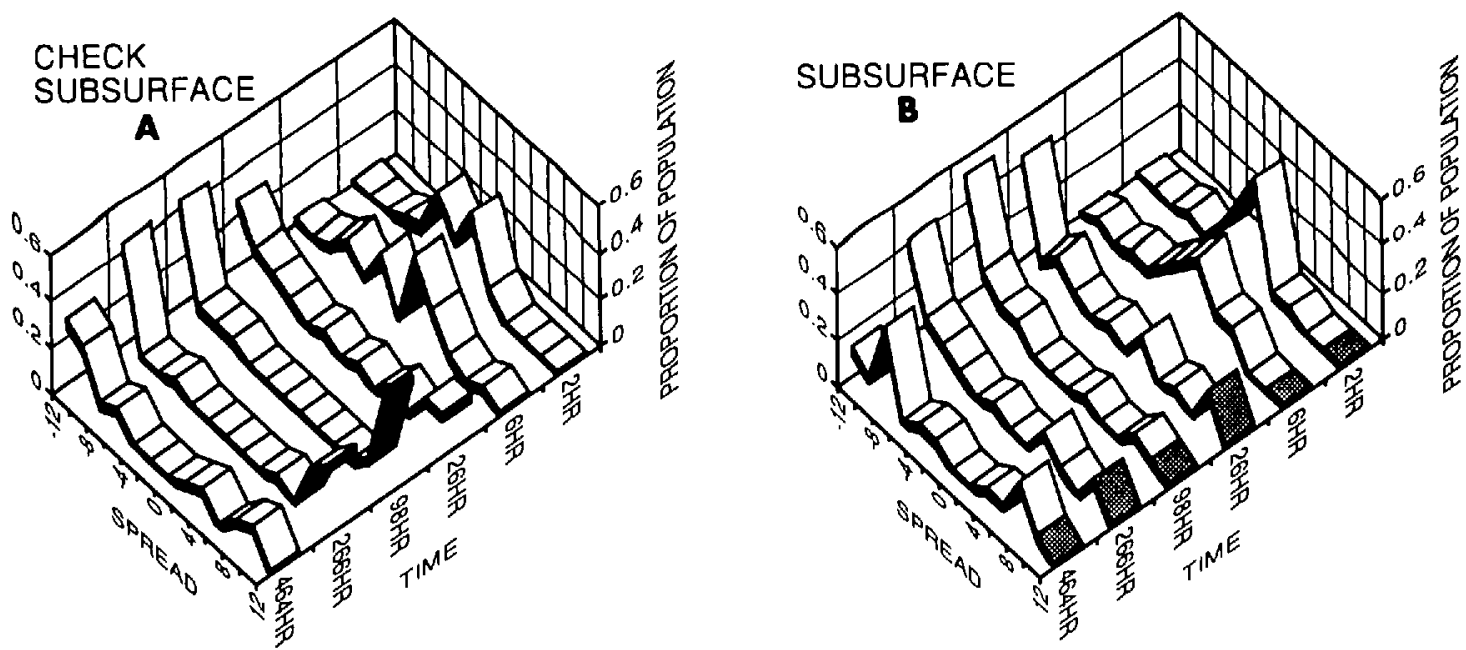

Fig. 7. Response of Japanese beetle grub population to the presence of subsurface applied mycelium. Graph indicates shifts in grub population ( $z$-axis) in radiographic microcosms ( $x$-axis) over time ( $y$-axis). Shaded area denotes presence of mycelial particles in chamber. 

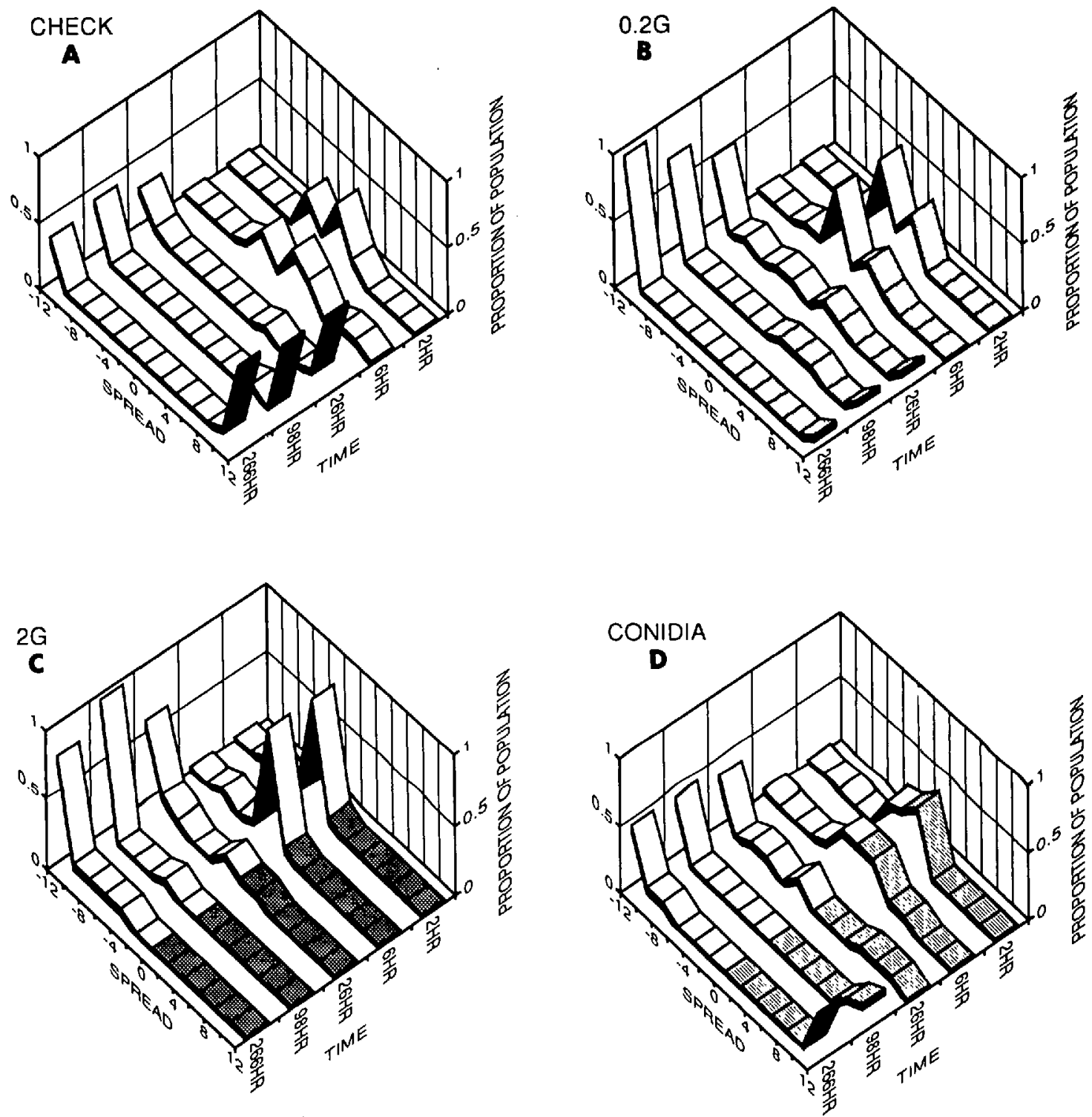

Fig. 8. Response of Japanese beetle grub population to the presence of untreated soil (A), incorporated mycelium at 0.2 (B), $2 \mathrm{~g}$ mycelium (C), and conidia (D), in $125 \mathrm{~g}$ of soil. Graph indicates shifts in grub population (zaxis) in radiographic microcosms $(x$-axis) over time ( $y$-axis). Shaded area denotes presence of mycelial particles in chamber.

untreated side $(13.17 \pm 2.52)$ of choice microcosms. The percentage of total eggs laid in the 'treated' side of each microcosm differed by $50 \%$ in the choice microcosms $(t=3.34 ; \mathrm{df}=17 ; P<$ $0.05)$. Significant differences between designated 'treated' and 'untreated' sides of no-choice check microcosms were not detected $(t=1.006$; $\mathrm{df}=17 ; P>0.05)$, nor were any detected in the no-choice mycelium microcosms $(t=0.833$; $\mathrm{df}=$ $17 ; P>0.05)$ indicating ovipositing females did not discriminate between the left and right sides of the 'treatment' arenas in the absence of treatment differences.

\section{Discussion}

Greenhouse Study. M. anisopliae inoculum remained localized at the site of application with no evidence of lateral or vertical movement of fungal propagules on all three sample dates. Our results are consistent with other laboratory and field studies that indicate minimal fungal movement in soil through time (Storey \& Gardner 1987, Storey \& Gardner 1988). No M. anisopliae was detected in the untreated microcosms on the first or second sample dates but a measurable level of M. anisopliae was detected in the bottom 
left section in one arena on the third sample date suggesting contamination or the presence of naturally occurring $M$. anisopliae. Overall fungal concentration was lower in the furrow application treatments despite equal application rates between the furrow and broadcast treatments. These data suggest that at a high density, selfinhibition of M. anisopliae occurs. We did not determine if the lower $M$. anisopliae concentration was due to the death of mycelium inoculum, or to a decrease in conidia production from the mycelium particles, nor was mechanism(s) leading to inhibition investigated.

On the first sample date, most grubs in the untreated microcosms were located in the top sections of each microcosm. Broadcast application of $M$. anisopliae mycelial particles to microcosms caused grubs to move downward. When $M$. anisopliae was applied to a center furrow in the microcosms, grubs moved down and to the sides away from $M$. anisopliae. These data suggest that grubs were repelled by some factor associated with the $M$. anisopliae application, and that grubs, in response to that factor, readily moved to untreated areas in the microcosms. The apparent ability of grubs to perceive the presence of fungus (or factors associated with the fungus), and the presence of refugia into which grubs can escape, may provide some explanation for the delay in grub mortality in the broadcast microcosms and low grub mortality in the furrow treatment. The lack of refugia in simple cup bioassays (Krueger et. al 1991, Krueger et al. 1992) probably contributed to high grub mortality rates in those studies. These results also suggest why the use of fungal pathogens have been most successful when no refugia for soil insects are available, for example, when pathogen is incorporated into soil to be used as a potting mix for woody ornamentals (Villani 1993).

At the second sample date, grubs were recovered in greater numbers in the top sections of all microcosms, although horizontal patterns in grub numbers remained similar to those found at the first sample date with respect to application treatment. These data indicate that grubs moved primarily vertical with little horizontal movement between sample dates one and two.

Grubs in the broadcast treatment moved strongly from the bottom of the microcosms to the root zone while grubs in the furrow treatment showed no such change in location relative to the zone in which the mycelial particles were applied. Possible explanations for this change in grub location between the first and second reading in the broadcast microcosms may be due to several factors including:

First, a shift in the 'factors' associated with the inoculum from repellent, to attractive or neutral in activity. This change in the nature of the active factor may be a change in the type of metabolites produced by the fungus and/or metabolites produced by soil microbes interacting with the inoculum. Grub populations in the furrow microcosms show no shift in position between the first and second reading, therefore, it appears unlikely that a shift in metabolite type is primarily responsible the differences we saw in grub location in broadcast microcosms. An alternative possibility is that the concentration of the 'factor' produced may have been responsible for the differences in grub location patterns in the broadcast and furrow microcosms. Soil insects are known to be attracted to or arrested by low $\mathrm{CO}_{2}$ gradients but repelled by high $\mathrm{CO}_{2}$ (and low $\mathrm{O}_{2}$ ) concentration (Villani and Wright 1990). The incorporation of inoculum into soil produced measurable increases of $\mathrm{CO}_{2}$ in the soil atmosphere around the inoculum, but these levels returned to near baseline within $24 \mathrm{~h}$ after introduction (Villani, unpub. data). Mycelial preparations of $M$. anisopliae have reported to produce bioactive metabolites that include chitinases, proteases (Charnley \& St. Leger 1991, St. Leger et al 1993) and entomotoxins (destruxins, and cytochalasins) (Roberts 1981) that may induce an avoidance response in grubs. Shifts in the response of soil insects based on the concentration of natural products are well documented (i.e. Ileshoji et al. 1980). The high concentration of inoculum in the center sections of the furrow microcosms may have allowed a critical concentration of the active factor in the center sections of the furrow microcosms.

Second, a shift in the grub's response to a mycelial particle-associated 'factor' from repellent, to attractive or neutral. Insects have also been shown to habituate to natural products thereby increasing the dosage required to illicit a response (Schoonhoven 1982). Additionally, because grubs in microcosms receiving broadcast application of the mycelial particles had not fed in the root zone during the first sample period it is feasible that hunger diminished the grubs' response to the mycelial particle-factor. In contrast, grubs in the furrow treatment showed no such change in behavior relative to the zone in which the mycelial particles were applied, perhaps because they could feed freely on the untreated sections of the microcosms.

Third, a shift in location of a 'repellent factor' from the top to the bottom of the broadcast microcosms. This is reasonable if products associated with the inoculum moved down through the soil profile, perhaps as a result of irrigation of the broadcast microcosms. The high concentration of inoculum in the center sections of the furrow microcosms may have reduced the importance of translocation of the factor in these microcosms.

By the third sample date, grubs were found in greater numbers in the bottom sections of the untreated microcosms and microcosms receiving a furrow application of $M$. anisopliae mycelial particles. This downward movement of grubs is 
consistent with the normal maturation process of Japanese beetles and the onset of pupation (Tashiro 1987, Villani \& Nyrop 1991). Grubs also moved down between the second and third sample dates in the broadcast treated microcosms but the movement was not as pronounced as in the furrow treatment microcosms or untreated microcosms. One can speculate that the reduced movement of grubs in the broadcast treatment may have been the result of a delay in grub development due to a lack of food, the presence of a repellent metabolite at the bottom sections of these microcosms, or sub lethal effects of $M$. anisopliae that affected grub mobility.

Radiography. Both experiments 1 and 2 show that the presence of $\boldsymbol{M}$. anisopliae mycelial particles in soil caused grubs to avoid inoculumtreated soil. Grub response to treated soil appeared to be rate-related because the grub's avoidance response to the lower rate of inoculum $(0.2 \mathrm{~g}$ mycelial particles in $125 \mathrm{~g}$ soil) was delayed when compared with the standard $(2 \mathrm{~g}$ mycelial particles in $125 \mathrm{~g}$ soil) application rate. This delayed response suggests that factors associated with the growing mycelium from particles build to some threshold before observable changes in grub behavior is manifested. Conidia caused no measurable grub behavioral response. This further supports our observation that factors associated with growing mycelium in soil caused shifts in grub movement patterns.

Grubs did not move into soil containing mycelial particles even when they had consumed all root material from the untreated end of the microcosms (and when they had consumed roots on both sides of check microcosms). The lack of grub feeding on roots in the treated side of the microcosms was consistent in both the incorporated and subsurface application of mycelium. These results differed from the greenhouse experiment where grubs moved into the upper sections of the microcosms at the second sampling date.

Oviposition. Although Japanese beetle grubs were repelled by the presence of $M$. anisopliae mycelial particles, these same particles seemed to promote oviposition activity of adult Japanese beetle in both choice and no choice experiments. Females presented with a choice between soil with and without mycelium consistently deposited more eggs in soil containing mycelial particles. Moreover, the presence of mycelium in soil in no choice microcosms increased the total number of eggs females oviposited when compared with similar no choice microcosms containing only untreated soils.

Previous studies have documented that Japanese beetle females discriminate between oviposition sites based on soil physical properties (Allsopp et al. 1992). Mycelia growing in the soil produce specific (Charnley \& St. Leger 1991, St. Leger et al 1993, Roberts 1981) and nonspecific metabolites (i.e. $\mathrm{CO}_{2}$ ). These nonspecific metabolites may mimic growing roots thereby increasing the perceived quality of these sites to female beetles. This response by females to mycelial particles or factors associated with mycelial particles may have increased oviposition activity and subsequently the number of eggs and first instar grubs in microcosm sites with high levels of inoculum. The active factors(s) affecting oviposition behavior of female beetles may not be the same as those responsible for avoidance behavior in grubs.

Conclusions. Previous reviews have suggested that the impact of soil physical properties can independently affect the persistence and spatial interactions of soil insects and fungal pathogens in soil (Villani \& Wright 1990, Villani \& Wright 1991, Villani et al. 1992). Clearly, these indirect factors may have a profound impact on the performance of fungal pathogens applied in the field for grub control. Less well documented are the possible direct interactions of insects and pathogens in the soil matrix. These direct interactions are of practical concerns when inundative soil applications of fungal pathogens are applied to soil for grub control but may have their origins in an evolved behavioral response of soil arthropods to pathogen-infected soil fauna.

Our studies indicate that the application of mycelial particles in soil affected the behavior of both larval and adult Japanese beetles. Although the hypothesis was not tested directly, our study suggests that factors associated with growing mycelium in soil is the basis for this activity. We have created a complex microcosm system that better simulates the field by providing refugia from the fungus or fungus related factors, thereby permitting avoidance behavior by grubs. Therefore, pathogen/insect interactions take place in a more realistic setting than in cup bioassays, and under a more manageable and observable environment than field testing permits. Our findings on scarab response to inundative applications of $M$. anisopliae mycelial particles may help explain some of the inconsistency in results that often occur when fungal pathogens are used to control insects in the field.

\section{References Cited}

Allsopp, P. G., M. G. Klein, \& E. L. McCoy. 1992. Effect of soil moisture and soil texture on oviposition by Japanese beetle and rose chafer (Coleoptera: Scarabaeidae). J. Econ. Entomol. 85: 2194-2200.

Chamley, A. K., \& R. J. St. Leger, 1991. The role of cuticle-degrading enzymes in fungal pathogenesis in insects, pp. 267-286. In G. T. Cole \& H. C. Hoch [eds.], The fungal spore and disease initiation in plants and animals. Plenum, NY.

Chase, A. R., L. S. Osborne, L. S., \& V. M. Ferguson. 1986. Selective isolation of the entomopathogenic fungi Beauveria bassiana and Metarhizium 
anisopliae from an artificial potting mixture. Fla. Entomol. 69: 285-292.

Fargues, J. F. 1976. Specificité des champignons pathogenes imparfaits (Hyphomycetes) pour les larves de coleopteres (Scarabaeidae et Chrysomelidae). Entomophaga, 21: 313-323.

Fargues, J. F. \& P. H. Robert. 1983. Effects of passing through scarabeid hosts on virulence and host specificity of two strains of the entomopathogenic hyphomycete Metarhizium anisopliae. Can. J. Microbiol. 29: 576-583.

Ferron, P. 1967. Etude en laboratoire des conditions ecologiques favorisant le developpement de la mycose a Beauveria tenella du ver blanc. Entomophaga 12: 257-293.

Hywel-Jones, N. L. \& A. T. Gillespie. 1990. Effect of temperature on spore germination in Metarhizitum anisopliae and Beauveria bassiana. Mycol. Res. 94: 389-392.

Ikeshoji, T., Y. Ishikawa, \& Y. Matsumoto. 1980. Attractants against onion maggots and flies, Hylema antiqua, in onions inoculated with bacteria. J. Pestic. Sci. 5: 343-45.

Johnson, R. A. \& D. W. Wichern. 1982. Applied multivariate statistical analysis. Prentice Hall, Englewood Cliffs, N.J.

Klein, M. G. 1988. Pest management of soil-inhabiting insects with microorganisms. Agric. Ecosys. Environ. 24: 337-349.

Krueger, S., M. G. Villani, J. P. Nyrop, \& D. W. Roberts. 1991. Effect of soil environment on the efficacy of fungal pathogens against scarab grubs in laboratory bioassays. J. Biol. Control 1: 203-209.

Krueger, S., M. G. Villani, A. S. Martins, \& D. W. Roberts. 1992. Efficacy of soil applications of Metarhizium anisopliae conidia, and standard and lyophilized mycelium particles against scarab grubs. J. Invertebr. Pathol. 59: 54-60.

Lingg, A. J. \& M. D. Donaldson. 1981. Biotic and abiotic factors affecting stability of Beauveria bassiana conidia in soil. J. Invertebr. Pathol. 38: 191200.

Milner, R. J. 1992. The potential of Metarhizium anisopliae for the control of scarab pests in groundnuts in Myanmar (Burma), pp. 277-280. In T. Jackson \& T. Glare [eds.], Pathogens in scarab pest management. Intercept, Andover, MA.

Rath, A. C. 1992. Beauveria bassiana for control of the Tasmanian pasture scarab Adoryphorus couloni, pp. 217-228. In T. Jackson \& T. Glare [eds.], Pathogens in scarab pest management. Intercept, Andover, MA.

Reid, R. N. \& R. H. Cherry. 1992. Effect of soil parameters on pathogenicity of the fungus Metarhizium anisopliae to the sugarcane grub Ligyrus subtropicus (Coleoptera: Scarabaeidae). Fla. Entomol. 75: 179-184.

Roberts, D. W. 1981. Toxins of entomopathogenic fungi, pp. 441-464. In H. D. Burges [ed.], Microbial control of pests and plant diseases 1970-1980. Academic, London.
Samuels, K.D.Z., D. E. Pinnick, \& R. M. Bull. 1990. Scarabeid larvae control in sugarcane using Metarhizium anisopliae. J. Invertebr. Pathol. 55: 135-137.

Schoonhoven, L. M. 1982. Biological aspects of antifeedants. Entomol, Exp. Appl. 31: 57-69.

St. Leger, R. J., R. C. Staples, \& D. W. Roberts. 1993. Entomopathogenic isolates of Metarhizium anisopliae, Beauveria bassiana, and Aspergillus flavus produce multiple extracellular chitinase isozymes. J. Invertebr. Pathol. 61: 81-84.

Studdert, J. P., H. K. Kaya, \& J. M. Duniway, 1990. Effect of water potential, temperature, and claycoating on survival of Beauveria bassiana conidia in loam and peat soil. J. Invertebr. Pathol. 55: 417427.

Storey, G. K. \& W. A. Gardner. 1987. Vertical movement of commercially formulated Beauveria bassiana conidia through four Georgia soil types. Environ. Entomol. 16: 178-182.

Storey, G. K. \& W. A. Gardener. 1988. Movement of an aqueous spray of Beauveria bassiana into the profile of four Georgia soils. Environ. Entomol. 17: 135-141.

Tashiro, H. 1987. Turfgrass Insects of the United States and Canada. Cornell University Press, Ithaca, NY.

Villani, M. G. \& R. J. Wright. 1988. Use of radiography in behavioral studies of turfgrass-infesting scarab grub species (Coleoptera: Scarabaeidae). Bull. Entomol. Soc. Am. 34: 132-144.

1990. Environmental influences on soil macro-arthropod behavior in agricultural systems. Annu. Rev. Entomol. 35: 249-269.

1991. Environmental considerations in soil insect pest management. In D. Pimentel [ed.], Handbook of pest management in agriculture 2 nd ed., vol. 1 . CRC, Boca Raton, FL.

Villani, M. G. \& J. P. Nyrop. 1991. Age dependent movement patterns of Japanese beetle and European chafer grubs in soil-turfgrass microcosms. Environ. Entomol. 20: 241-251.

Villani, M. G., S. R. Krueger, \& J. P. Nyrop. 1992. Interaction of scarab grubs and microbial pathogens in the soil environment, pp. 111-126. In T. Jackson \& T. Glare [eds.], Pathogens in scarab pest management. Intercept, Andover, MA.

Villani, M. G. 1993. 1992 Cornell Turfgrass Research Report. Cornell University Press, Ithaca, NY.

Walstad, J. D., R. F. Anderson, \& W. J. Stambaugh. 1970. Effects of environmental conditions on two species of muscadine fungi (Beauveria bassiana and Metarhizium anisopliae). J. Invertebr. Pathol. 16: 221-226.

Zimmerman, G. 1992. Use of the fungus, Beauveria brongniartii, for control of European cockchafers, Melolontha spp., in Europe, pp. 199-208. In T. Jackson \& T. Glare [eds.], Pathogens in scarab pest management. Intercept, Andover, MA.

Received for publication 3 September 1993; accepted 1 December 1993. 